\title{
Type 2 diabetes mellitus in a cohort of Finnish patients with hidradenitis suppurativa
}

\section{Kluger, Nicolas}

2020-02

Kluger , N, Nuutinen, P , Lybeck, E, Ruohoalho , T T \& Salava, A 2020 , ' Type 2 diabetes mellitus in a cohort of Finnish patients with hidradenitis suppurativa ', Journal of the European Academy of Dermatology and Venereology , vol. 34 , no. 2 , 31596976 , pp. e98-e100 . https://doi.org/10.1111/jdv.16010, https://doi.org/10.1111/jdv.16010

http://hdl.handle.net/10138/313112

https://doi.org/10.1111/jdv.16010

acceptedVersion

Downloaded from Helda, University of Helsinki institutional repository.

This is an electronic reprint of the original article.

This reprint may differ from the original in pagination and typographic detail.

Please cite the original version. 
DR. NICOLAS KLUGER (Orcid ID : 0000-0002-5225-8316)

Article type : Letter to Editor

Journal of the European Academy of Dermatology and Venereology

Type: Letter to Editor

Type 2 diabetes mellitus in a cohort of Finnish patients with hidradenitis suppurativa

Nicolas Kluger, MD, PhD; Pauliina Nuutinen, MD; Emilia Lybeck, MD; Timo Ruohoalho, MD;

Alexander Salava, MD, PhD

Department of dermatology, allergology and venereology, Helsinki University Central Hospital, Helsinki, Finland

Key-words: comorbidities, diabetes type 2, epidemiology, hidradenitis suppurativa

Corresponding author: Nicolas Kluger

nicolas.kluger@hus.fi

This article has been accepted for publication and undergone full peer review but has not been through the copyediting, typesetting, pagination and proofreading process, which may lead to differences between this version and the Version of Record. Please cite this article as doi: 10.1111/JDV.16010

This article is protected by copyright. All rights reserved 
Conflict of interest:

Dr. Nicolas Kluger has served as a consultant to AbbVie, and has received research funding from AbbVie and speaker fees from AbbVie (2015-2016)

Alexander Salava: no conflicts of interest

Words: 660

Funding sources: no funding

References: 8

Table: 1

Editor,

Hidradenitis suppurativa (HS) has been associated with metabolic syndrome [1-3]. Three large population-based studies showed a significant association of type 2 diabetes mellitus (T2DM) with HS [3-5]. Two meta-analyses found an increased 1.69 to 3 odds of diabetes [6-7]. In the present study, we aimed to compare whether the phenotype and comorbidities of HS patients with T2DM would differ from those without T2DM. We reviewed retrospectively all the patients with HS diagnosis that attended a tertiary care hospital (Department of dermatology, Helsinki University Hospital, Finland) between January and December 2018. Current age (at inclusion in the study, in 2018), age at HS onset (when symptoms first occurred) and at HS diagnosis, family history, smoking, comorbidities, Hurley stages and affected body sites were inquired in each 
patient. As the study relied on the centralized medical reports of our patients, including both university hospital and primary healthcare with no direct patient contact, no ethical committee statement was required. The data was based on analyzing patient records, which were anonymized before study inclusion, and the gathering of patient data for the study.

A total of 166 patients was included in this study (96 women, mean age $\pm S D=38.4 \pm 13.8$ years). The prevalence of T2DM in the present cohort was $15.7 \%(n=26)$. Sixteen patients have already T2DM at the time of HS was diagnosis. Table 1 summarizes patients' main characteristics. Briefly, HS patients with T2DM had a later age at onset of HS (36.1 vs. 25.1 years, Student t-test, $\mathrm{p}=0.001)$. Among the patients for whom staging was available, patients with T2DM displayed more frequently Hurley stage III (58.3\% [7/12] vs $12.8 \%$ [9/70], $p=0.001)$. There were no statically significant differences regarding family history, body mass index, and anatomical location of HS. Among comorbidities, there was no difference regarding acne, pulmonary disorders (asthma, chronic bronchitis, sleep apnea), hypothyroidism, psychiatric disorders or inflammatory disorders. Patients with T2DM had higher frequencies of cardio-vascular conditions such as hypertension $(p<0.0001)$, coronary disease $(p=0.005)$, hypercholesterolemia $(p=0.0007)$ and gout $(p=0.001)$, lower limb arteriopathy $(p=0.012)$, and past or present smoking $(p=0.034)$. Binary logistic regression (taking into account gender, age, smoking, hypertension, coronary disease, lower limb arteriopathy, gout, dyslipidemia and overweight/obesity) showed that only hypertension (OR 8.4 [2.0-36.0], $p=0.004$ ) was significantly associated with T2DM among patients with HS.

The proportion of T2DM in our cohort was $15.7 \%$, which is in line with ranges from the literature (4.5-25\%) [1-7]. The link of causality between T2DM and HS is not known [1,6]. HS may promote T2DM through chronic inflammation with elevated TNF- $\alpha$, or insulin resistance may predispose to HS [1]. Although we found here that T2DM preceded HS diagnosis for $61 \%$ of the patients, we cannot confirm a temporal relationship between T2DM and HS. We did not have any T2DM time of diagnosis. Besides, delay of diagnosis can be long and patients may have had HS for a longer period [8] before even T2DM onset. Patients with T2DM seemed to have a more severe disease according to Hurley stages. To the best of our knowledge, severity of HS in patients with T2DM has never been shown. The low number of patients for which staging was available $(46 \%$ of the 
patients with T2DM) limits our results. T2DM could influence the severity of HS. We found that patients with T2DM was only associated with hypertension. Obesity, smoking and other cardiovascular comorbidities were not associated on the multivariable analysis. The main limitation of our study was the relatively small patient cohort and significant associations might have remained unrecognized due to the small patient sample. Additionally, based on the tertiary university hospital setting, a selection bias of severe patients should be recognized.

Acknowledging the limits of our study, we failed to find in our cohort any specific phenotype for patients with T2DM and HS except a higher frequency of hypertension. Monitoring for T2DM during HS remains warranted $[6,7]$, even if the link of temporal causality between T2DM and HS is unclear. T2DM could be a factor of severity for HS patients, but larger comparative studies are needed to confirm or infirm this hypothesis.

\section{References}

1. Gold DA, Reeder VJ, Mahan MG, Hamzavi IH. The prevalence of metabolic syndrome in patients with hidradenitis suppurativa. J Am Acad Dermatol. 2014;70:699-703.

2. Miller IM, Ellervik C, Vinding GR, Zarchi K, Ibler KS, Knudsen KM, Jemec GB. Association of metabolic syndrome and hidradenitis suppurativa. JAMA Dermatol. 2014;150:1273-80.

3. Shalom G, Freud T, Harman-Boehm I, Polishchuk I, Cohen AD. Hidradenitis suppurativa and metabolic syndrome: a comparative cross-sectional study of 3207 patients. Br J Dermatol. 2015;173:464-70.

4. Garg A, Birabaharan M, Strunk A. Prevalence of type 2 diabetes mellitus among patients with hidradenitis suppurativa in the United States. J Am Acad Dermatol. 2018;79:71-76. doi: 10.1016/j.jaad.2018.01.014

5. Lee JH, Kwon HS, Jung HM, Kim GM, Bae JM. Prevalence and comorbidities associated with hidradenitis suppurativa in Korea: a nationwide population-based study. J Eur Acad Dermatol Venereol. 2018;32:1784-1790. doi: 10.1111/jdv.15071..

6. Bui TL, Silva-Hirschberg C, Torres J, Armstrong AW. Hidradenitis suppurativa and diabetes mellitus: A systematic review and meta-analysis. J Am Acad Dermatol.2018;78:395-402.

This article is protected by copyright. All rights reserved 
7. Phan K, Charlton O, Smith SD. Hidradenitis suppurativa and diabetes mellitus: updated systematic review and adjusted meta-analysis. Clin Exp Dermatol. 2019 Feb 7. doi: 10.1111/ced.13922.

8. Kluger N, Ranta M, Serlachius M. The Burden of Hidradenitis Suppurativa in a Cohort of Patients in Southern Finland: A Pilot Study. Skin Appendage Disord. 2017;3:20-27. 
Table 1. Disease characteristics in HS patients with and without diabetes type 2

\begin{tabular}{|c|c|c|c|}
\hline & T2DM & No T2DM & $\begin{array}{l}\text { Fisher's exact test } \\
\text { Student t-test } \\
\text { P-value }\end{array}$ \\
\hline$n$ & $26(15.7)$ & $140(84.3)$ & \\
\hline $\begin{array}{l}\text { Gender } \\
\text { Male, n (\%) }\end{array}$ & $16(61.0)$ & $54(38.0)$ & 0.033 \\
\hline Mean age (SD) & $53.4(13.0)$ & $35.7(12.1)$ & $<0.001$ \\
\hline $\begin{array}{l}\text { Mean age at diagnosis } \\
\text { in years (SD) }\end{array}$ & $46.8(13.7)$ & $32.0(11.7)$ & $<0.001$ \\
\hline $\begin{array}{l}\text { Mean age at first } \\
\text { symptoms in years } \\
\text { (SD) }\end{array}$ & $36.1(13.2)$ & $25.1(11.2)$ & 0.001 \\
\hline Familial history of HS & $4(40.0)$ & $22(42.3)$ & 1.000 \\
\hline \multicolumn{4}{|l|}{ Hurley classification } \\
\hline Hurley I & - & $34(48.6)$ & \\
\hline Hurley II & $5(41.7)$ & $27(38.6)$ & \\
\hline Hurley III & 7 (58.3) & $9(12.8)$ & 0.001 \\
\hline \multicolumn{4}{|l|}{ Smoking } \\
\hline Ever smokers & $23(95.8)$ & $94(70.7)$ & 0.034 \\
\hline Active smokers & $11(45.8)$ & $71(53.4)$ & 0.523 \\
\hline \multicolumn{4}{|l|}{$\begin{array}{l}\text { BMI at inclusion, } \\
\mathrm{kg} / \mathrm{m}^{2}\end{array}$} \\
\hline Mean (SD) & $34.0(7.3)$ & $32.1(8.0)$ & 0.817 \\
\hline $\mathrm{BMI} \geq 25$ & $21(80.8)$ & $99(70.7)$ & 0.348 \\
\hline Obesity (BMI $\geq 30)$ & $16(61.5)$ & $68(48.6)$ & 0.287 \\
\hline \multicolumn{4}{|l|}{ Cardio-vascular } \\
\hline Hypertension & $16(61.5)$ & $21(15)$ & $<0.00001$ \\
\hline Arrhythmia & $3(11.5)$ & $6(4.3)$ & 0.154 \\
\hline Heart infarct & $4(15.4)$ & - & 0.0005 \\
\hline
\end{tabular}




\begin{tabular}{|l|l|l|l|}
\hline Heart insufficiency & $2(7.7)$ & $1(0.7)$ & 0.064 \\
\hline Low limb arteriopathy & $3(11.5)$ & $1(0.7)$ & 0.012 \\
\hline Stroke & $1(3.8)$ & $2(1.4)$ & 0.402 \\
\hline Gout & $5(19.2)$ & $2(1.4)$ & 0.001 \\
\hline Dyslipidemia & $10(38.5)$ & $8(5.7)$ & 0.000 \\
\hline Hypercholesterolemia & $8(30.8)$ & $8(5.7)$ & 0.0007 \\
\hline Thyroid disease & 2 (7.7) & $18(12.8)$ & 0.742 \\
\hline Lung disorders & & & 0.051 \\
\hline Uniapnea & 7 (26.9) & $15(10.7)$ & \\
\hline $\begin{array}{l}\text { Autoimmune and } \\
\text { inflammatory } \\
\text { disorders }\end{array}$ & & $12(8.6)$ & 0.375 \\
\hline Psoriasis & 2 (7.7) & $7(5.0)$ & 0.598 \\
\hline $\begin{array}{l}\text { Inflammatory bowel } \\
\text { disease* }\end{array}$ & - & $53(37.8)$ & \\
\hline $\begin{array}{l}\text { Inflammatory joint } \\
\text { disease** }\end{array}$ & - & & \\
\hline Psychiatric diseases & 7 (26.9) & & \\
\hline $\begin{array}{l}\text { T2DM: Diabetes type 2; SD : Standard Deviation } \\
\text { * Includes Crohn's disease and ulcerative colitis }\end{array}$ & & \\
\hline
\end{tabular}

